\title{
Developing and Implementing an Environmental Performance Index for the Portuguese Military
}

\author{
Tomás B. Ramos ${ }^{1 *}$ and João Joanaz de $\mathrm{Melo}^{2}$ \\ ${ }^{1}$ University of the Algarve, Portugal \\ ${ }^{2}$ New University of Lisbon, Portugal
}

\begin{abstract}
At an international level, the implementation of environmental management practices in military facilities is now a growing reality, particularly with the implementation of environmental management programmes and/or systems. The main goal of this research was to assess the Portuguese military sector's environmental performance through an index - the MEPE index - in a simplified and useful manner. A second goal was to measure the units' self-assessment against the environmental profile of the military sector as evaluated through the index, to determine how far they match. The index was deeloped on the basis of the data obtained in a national questionnaire, which was carried out to evaluate environmental practices adopted by military units. Results show that the Portuguese military's overall environmental performance is poor, reflecting that this is quite a new issue in military organizations. Among the military branches the Air Force reveals the best environmental results.
\end{abstract}

Received 7 January 2004, revised 10 June 2004, accepted 5 August 2004

Keywords: military sector; environmental practices; environmental performance index; decision-makers

\section{Introduction}

A

$S$ IN THE PRIVATE SECTOR, GOVERNMENTS AND PUBLIC ORGANIZATIONS REALIZE THAT THEIR activities need to be managed in a sustainable way. The defence sector oversees an important number of operations and activities that are carried out by the different military branches, i.e. the

Navy, Army and Air Force and their administrative divisions. Part of the defence sector's work is specifically military, e.g. weapons training, but many of the activities are equivalent to their counterparts in civilian society, such as the heating of buildings or transportation using commercial-type vehicles.

At the international level, governments and certain defence organizations have swiftly understood the role of environmental management in peacetime defence organizations. Therefore, implementation of 
environmental management practices in military facilities is now a growing reality, particularly with the implementation of environmental management programmes and/or systems. Programs such as the UK initiative Sustainable Development in Government (UK Government, 2002) or the Canadian 'Greening government' (PMSGO, I999) are important steps for the whole public sector, which also involves the defence domain. In wartime the priorities change and accomplishment of the military mission is the main concern. Nevertheless, although most environmental guidelines, policies and standards for defence focus on peacetime (e.g. Portuguese Environmental Policy for the Defence Sector, MDN, 200I, or Environmental Guidelines for the Military Sector, NATO, I996), certain environmental management considerations should be implemented permanently. Moreover, the distinction between peacetime and wartime is becoming blurred. On one hand, we are already engaged in an unconventional and undeclared war on terrorism. On the other hand, today more and more peacekeeping or combat missions are carried out among civilian populations that are supposed to be protected, not harmed; for operational purposes, safety and environmental standards should be enforced as a general rule, whether those missions are conducted under a declared state of war or not. Bosnia, Kosovo and Iraq are examples of such situations.

Many environmental management practices could have results in both peace and wartime, particularly many environmental measures under the systems acquisition processes, such as environmentally adapted small calibre ammunition (e.g. the original lead-and-steel core was replaced with a homogenous steel core (US DOD and SAF, I999) or alternative fuel vehicles, among others. Actually, some military forces are becoming aware of this aspect and trying to integrate certain environmental issues into their activities during all kinds of military operation (e.g. US Army, 200I). The NATO Standardization Agreement for Environmental Protection (NATO, 2002) does not exclude operational activities, although it lays down important considerations for training exercises. This standard was published with the aim of stating the environmental doctrine for NATO-led operations and exercises and providing guidance in environmental planning for all military activities.

Various research works have surveyed and identified environmental management practices by different firms (e.g. Florida and Davison, 200I; Richards and Armstrong, I996; Lober et al., I997; DavisWalling and Batterman, 1997; Rowe and Enticott, I998; KPMG, 1999, 2002; Jones, I999; Stanwick and Stanwick, 2000; Theyel, 2000; Niskanen and Nieminen, 200I) and, in particular, environmental performance evaluation and reporting by organizations (e.g. Niskanen and Nieminen, 200I; Kolk et al., 200I; Noci, 2000; KPMG, I999; Jones, I999; Perry and Sheng, I999; Wilson and Sasseville, I999; Ranganathan, I998; Davis-Walling and Batterman, I997; UNEP and SustainAbility, I997; Lober et al. I997; Epstein, I996). This scenario differs from the lack of research on public sector environmental management practices, including performance evaluation and reporting.

Despite the dearth of literature on the incorporation of environmental management into defence activities, a certain amount of work has been carried out. On an international level the Committee on the Challenges of Modern Society (CCMS) of the North Atlantic Treaty Organization (NATO) was a pioneer in this field with the work carried out in the Pilot Study on Environmental Management Systems in the Military Sector (NATO, 2000). Additionally, several military organizations throughout the world are adopting EMS and/or environmental programmes for defence organizations, particularly in Australia, Canada, Spain, Sweden, the United Kingdom and the United States (see e.g. Lederer, I997; LFC/DND/CF, I999; Drawbaugh, I999; NATO, 2000; Steucke, 2000; US MC, 2000; US DOD, 2000; Taylor et al., 200I). The work by the Office of Enforcement and Compliance Assurance of the United States Environmental Agency (USEPA, I994) should also be mentioned. They attempt to evaluate how defence-related agencies (departments of the Army, Navy, Air Force and Energy), private sector corporations and civilian federal agencies perform against a benchmark developed to represent 
ideal organizational, managerial and operational performance in the execution of environmental responsibilities.

Environmental performance communication and measurement is a very important step in all environmental management processes, helping decision-makers and the general public to understand environmental information. The role of stakeholders is a major issue in private sector activities and should also be in public services, including defence missions and activities. As in the public sector generally, defence has different external and internal stakeholders and interested parties, including its civilian and military constituents, local communities and governments, non-governmental organizations and all taxpayers. Due to the role of the military and to the close proximity of many communities and military installations, cooperation with stakeholders is a central issue. As stressed by Jones et al. (2002), the news headlines show that the effects of military training are increasingly an issue of public concern.

Military training and operations are dependent upon public support, particularly that of neighbouring communities where military personnel work and live. This is of particular importance when many of the activities affect the environment outside the perimeter of the military facilities. As mentioned in NATO (I996), in many countries this collaboration has been put into practice through the establishment of a formal committee made up of members from the military sector, local community leaders and representatives of environmental groups. To convey the environmental information to stakeholders, tools such as indicators and indices that transform raw environmental data into easily understandable information are usually applied, namely at a corporate level (see, e.g., Berkhout et al., 200I; Olsthoorn et al., 200I; National Academy of Sciences, I999; Young and Welford, I998; Ditz and Ranganathan, I997; Azzone et al., I996; Tyteca, I996). Environmental performance indicators are already being used in the defence sector, as suggested in the works of NATO (2000) or DND/CF (I997), though their development is only just beginning.

The main objective of this research was to assess the Portuguese military sector's environmental performance through an index - the Military Environmental Performance Evaluation (MEPE) index - as the first step towards evaluating its environmental performance at national level, in a simplified and useful manner. In 2003 the MEPE index was proposed to the Portuguese Ministry of Defence by university researchers. This tool was designed to help decision-makers understand the sector's environmental signals. The index measures the extent to which a variety of environmental practices have been adopted.

Another goal was to measure how far the sector's self-assessment and the environmental performance matched each other, as measured by the index.

The index was developed with data obtained from a national questionnaire. This survey was proposed and conducted by university researchers for the Portuguese Ministry of Defence (MDN), under a research project on environmental management practices in military organizations.

\section{The Portuguese Military}

According to MDN (2002), the Portuguese military sector's effective manpower stands at 42700 , compared with 62300 in I990. The total number for personnel (civilian and military) employed in the Portuguese defence sector is about 56 200. The total cost of the Portuguese armed forces represents I.2\% of GDP. The Portuguese military is one of the largest organizations in the public sector, with many civilian employees, servicemen and women and reservists. As in other countries, the military is a very important property owner in Portugal (about 23 I35 hectares of land, according to MDN (2002), or about 
$0.25 \%$ of Portuguese territory). Some of that land has important natural assets that require specific care, representing added environmental responsibility in military units.

Until now, the Portuguese military sector's environmental performance has hardly been known. Apart from certain sporadic activities (e.g. marine pollution control and surveillance conducted by the Navy and Air Force), for many years national defence policy was far removed from environmental concerns and environmental management practices. Recently, the Portuguese Ministry of Defence (MDN) has demonstrated increasing interest in developing a better environmental profile. Several initiatives have been taken by the MDN and the military branches to integrate good environmental practices into the defence sector. Two military units have already implemented environmental management systems (EMSs): an Air Force training camp, Campo de Tiro de Alcochete, CTA (certified by ISO I4OOI) and the Army geographic survey agency Instituto Geográfico do Exército, IGeoE. The Air Force's CTA had the first EMS implemented in the Portuguese military and was a pioneer in the entire Portuguese public sector.

\section{Questionnaire on Environmental Management Practices}

Raw data on environmental management practices was obtained from a national questionnaire survey (Ramos and Melo, in press). The aim of the questionnaire was to evaluate the environmental practices in this sector, represented by the three branches of the Portuguese armed forces: the Army, Air Force and Navy (including marines), on the basis of self-assessment by the services. If implemented, these environmental practices could theoretically make a positive contribution to a better environmental performance. They include the appointment of a person responsible for the environment, environmental training for personnel, knowledge and implementation of environmental management systems, environmental programmes, environmental cooperation with stakeholders and environmental standards for suppliers, among others.

The questionnaire was targeted at the main units, bases, garrisons, agencies and commands of the Portuguese armed forces. The general term unit was adopted to represent all the different kinds of military organization focused on in the study.

The questionnaire had a total of 48 questions (open- and closed-ended questions) about environmental practices and about environmental performance, drawn from practical and theoretical scientific, technical and military information. Several criteria were used to derive the statistical population: (i) geographical coverage of the whole country, by NUTS II region (according to the NUTS European administrative classifications) - Alentejo, Algarve, Lisboa e Vale do Tejo, Centro, Norte, Açores and Madeira; (ii) a proportional number of units from each military branch; (iii) different types of natural and human environment bordering the military units (e.g. urban, rural, industrial and natural areas); (iv) variations in the size of the units (according to staff numbers or the land area allocated or vessel area) and (v) coverage of the great diversity of environmental impacts related to military missions. Additionally, only the military units that fulfil the following three conditions were considered: (a) they have a specific military mission; (b) their resource management is relatively autonomous (e.g. material/equipment and personnel) and (c) they have a specific land or vessel area allocated. The entire population was surveyed.

The questionnaire was posted in July 2000 to the $\mathrm{I} 33$ target military units. More specifically, it was sent from the Portuguese Minister of Defence's Office to the Commander-in-Chief of each military branch (Table I) and hence to the selected units (representing $44 \%$ of the total number of Portuguese military units, and a higher proportion of personnel). I27 units returned usable responses to the questionnaire, a response rate of $96 \%$. This high level of response was registered due to the specificity of 


\begin{tabular}{lcccc}
\hline & $\begin{array}{c}\text { Total units } \\
\text { (No.) }\end{array}$ & $\begin{array}{c}\text { Population } \\
\text { (No.) }\end{array}$ & $\begin{array}{c}\text { Usable respondent } \\
\text { units (No.) }\end{array}$ & $\begin{array}{c}\text { Response rate } \\
(\%)\end{array}$ \\
\hline Military sector & 300 & 133 & 128 & 96 \\
Army & 142 & 53 & 47 & 89 \\
Air force & 53 & 15 & 14 & 93 \\
Navy & 105 & 65 & 65 & 100 \\
\hline
\end{tabular}

Table 1. Portuguese military units: total units, population and respondents

the military sector, based on a strict hierarchical chain of command that usually results in an efficient implementation of orders from a higher level.

\section{The Military Environmental Performance Evaluation Index (MEPE)}

The raw data obtained in the above-mentioned survey of environmental management practices in the Portuguese military is quite extensive and diverse. To convey the whole environmental performance information to policy decision-makers and to military commanders or chiefs, an aggregation approach was adopted: the MEPE index.

The construction of the MEPE index was based on the questionnaire. One or more environmental practices are related to each indicator selected. Several indicators are meaningful only for the overall sector. As a result of this selection process I8 variables were selected (Table 2) to be aggregated by the index.

We should point out the difference between indicators and indices, as used in this work. Indicators may be defined as environmental variables that are measured directly or readily computed from indirect measurement and represent the phenomena under consideration. An environmental indicator is derived from a single variable to reflect some environmental attribute and can be used individually or aggregated into an environmental index. Indices are composed by classification and aggregation of one or more indicators, by means of mathematical or heuristic algorithms; they are usually presented according to some conventional, arbitrary scale.

Variables were selected as indicators according to a qualitative expert knowledge assessment of their relevancy to and feasibility in this assessment. The relevancy criterion covers their (i) technical and scientific importance, (ii) synthesis capability, in particular at sector level, (iii) usefulness for communicating and reporting, (iv) reflection of major environmental practice issues in defence organizations and (v) importance to the environmental head in the defence sector. The feasibility criterion covers various data aspects: (i) robustness, (ii) availability to future assessments and (iii) non-confidentiality. These criteria were applied taking into account the central goal of helping high level defence decision-makers understand sectoral environmental signals.

After the selection of indicators a normalization procedure was used to transform the raw data into a single continuous scale of variation $[0, \ldots, \mathrm{I}]$, thus allowing the aggregation processes. $\mathrm{O}$ is the worst environmental value, I the best. The MEPE index was computed using the following equation:

$$
M E P E=\sum_{j=\mathrm{I}}^{m} \frac{\left[\frac{\mathrm{I}}{\sum \mathfrak{w}} \sum_{i=\mathrm{I}}^{n} X_{i} \mathfrak{w}_{i}\right]_{j}}{m}
$$


Variable

Summary

Individual with environmental responsibility

Time spent by the environmental head

Other personnel with environmental tasks

Time spent by the other personnel with environmental tasks

Environmental studies/projects/plans

Environmental training

Environmental laws and regulations

Environmental services

Environmental management systems (EMS) knowledge

EMS implementation

Environmental programme implementation

Internal environmental regulations/standards

Environmental considerations in operational and logistical activities

Environmental considerations in contracts with suppliers

Procedures to collect, store and analyse environmental data and information

Environmental data

Environmental reporting

Environmental cooperation
A person in charge of environmental issues (coordinator/delegate). Environmental expert to advise the commander and to execute the programme.

Time spent by the person in charge of environmental responsibilities in relation to total daily tasks.

Besides the staff member in charge of all environmental issues, the unit can have other personnel allocated to environmental tasks.

Time spent by the other personnel with environmental tasks in relation to total daily tasks.

Unit's implementation of environmental studies, projects or plans, e.g. environmental impact statements, environmental audits, land-use management plans or environmental research projects.

Military staff subjected to environmental training courses.

Knowledge of environmental laws and regulations of interest to the unit.

Public services provided by military units.

EMS knowledge at unit command level.

State of EMS implementation.

State of environmental programme implementation.

Adoption of specific environmental-military internal regulations beyond the general environmental legislation.

Integration of environmental considerations in planning and implementing different operational and logistics activities, e.g. wheeled and tracked vehicle training.

Integration of environmental considerations in the systems acquisition process (e.g. acquisition of military equipment) - specifically in contracts with suppliers.

Regular procedures for collecting, storing and analysing environmental data and information.

Raw data availability for at least one environmental domain (e.g. water, air, soil, wastes or noise).

Units that have periodically presented environmental information in environmental reports or within another type of report.

Environmental cooperation with external stakeholders (e.g. NGOs, municipalities, local communities or ministerial departments).

Table 2. Variables used to compute the MEPE index

where

$X_{i}=$ the indicator of environmental practice $i$ derived from the questionnaire, which is attributed a relative weight, $w$

$n=$ the total number of $i$ indicators

$m=$ the total number of $j$ units.

In order to consider the relative importance of each different indicator, the MEPE index allows for weighting, but for the Portuguese military the MEPE index was computed with equal weights for each indicator.

Five categories were defined to classify the environmental performance provided by the index, in a range from $\mathrm{O}$ to I: very poor, $0-0.20$; poor, $0.2 \mathrm{I}-0.40$; medium, $0.4 \mathrm{I}-0.60$; good, $0.6 \mathrm{I}-0.80$, and excellent, o.8I-I. 
The MEPE index is not designed to evaluate the environmental performance of any individual military unit; i.e. this evaluation does not rank the respondent units. The MEPE analysis was conducted for each military branch and for the entire Portuguese military sector. The results were discussed taking into account a military unit's population size. To investigate potential differences among the MEPE index groups a non-parametric test, the Kruskal-Wallis test (Gibbons, I993; Wheater and Cook, 2000), a oneway analysis of variance using ranks, was performed. The test was done on several types of group: (i) the military branch, Army, Air Force and Navy; (ii) the personnel (military plus civilian) working in the unit, 2I classes of personnel, considering an increment of too individuals between consecutive classes $\left(\mathrm{CL}_{\mathrm{I}}=0-\mathrm{IOO}\right.$ individuals, $\left.\mathrm{CL}_{2}=\mathrm{IOI}-200, \ldots\right)$, and (iii) the land area: four area classes $(<\mathrm{I} 50 \mathrm{ha}$;

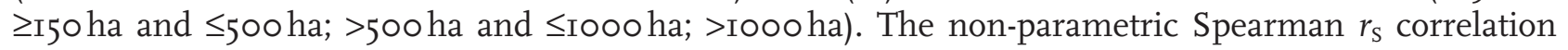
test was performed to assess the relations between MEPE and unit population size, and unit area.

A comparison was also carried out between the sector's environmental performance self-assessment and its environmental performance evaluated using the methodology proposed. This was done comparing the unit's answers to a single environmental performance self-assessment question and the MEPE results. The five MEPE categories are the same as used in the question 'the unit's environmental performance self-assessment', where numerical values are associated with ordinal data (in this case I-5, for poor to excellent). This comparison was based on the transformation of the MEPE index metric values into non-metric ordinal values for each class (very poor, I; poor, 2; medium, 3; good, 4, and excellent, 5), allowing association with the same discrete data as obtained in the question mentioned. The non-parametric Spearman $r_{\mathrm{S}}$ correlation test was performed to assess this relationship.

Since the question about the units' environmental performance self-assessment was developed using a Likert scale, which generally associates numerical values with ordinal data (in this case I-5 for poor to excellent) it was possible to calculate the arithmetic mean as suggested by Rea and Parker (I997). This procedure was applied to the MEPE index and to the self-assessment question, with both expressed in non-metric ordinal values.

Index sensitivity evaluation was accomplished through the use of correlation tests (non-parametric Spearman $r_{\mathrm{S}}$ ) among the indicators that compose the MEPE index and the index results.

\section{Results and Discussion}

\section{The MEPE Index by Service Branch}

MEPE results for the Portuguese military sector (0.33) show that the integration of environmental practices into Portuguese military activities is quite new, presenting a poor environmental performance, when classified according to the index classes (Figure I). The Air Force has the highest value (0.52), revealing the best performance among the three branches. This difference in the environmental performance of the Air Force is confirmed by the results of the Kruskal-Wallis test (significant for $p<0 . \mathrm{OI}$ ) (Table 3). The Air Force has the highest percentage of units classified as good (50\%) and medium (29\%).

The existence in the Air Force of several ongoing and/or already implemented environmental management practices under the Air Force environmental policy adopted could explain this better performance. Examples of such practices are that the majority of units have a person in charge of environmental issues, some units are implementing EMS and the majority of the units have environmental training activities. The organizational structure of this branch, with well defined environmental responsibilities at different levels and with units less widespread over the national territory, could lead to easier management of environmental aspects in general. Additionally, several initiatives are being taken by the Air Force to ensure a better environmental performance, specifically, the national envi- 


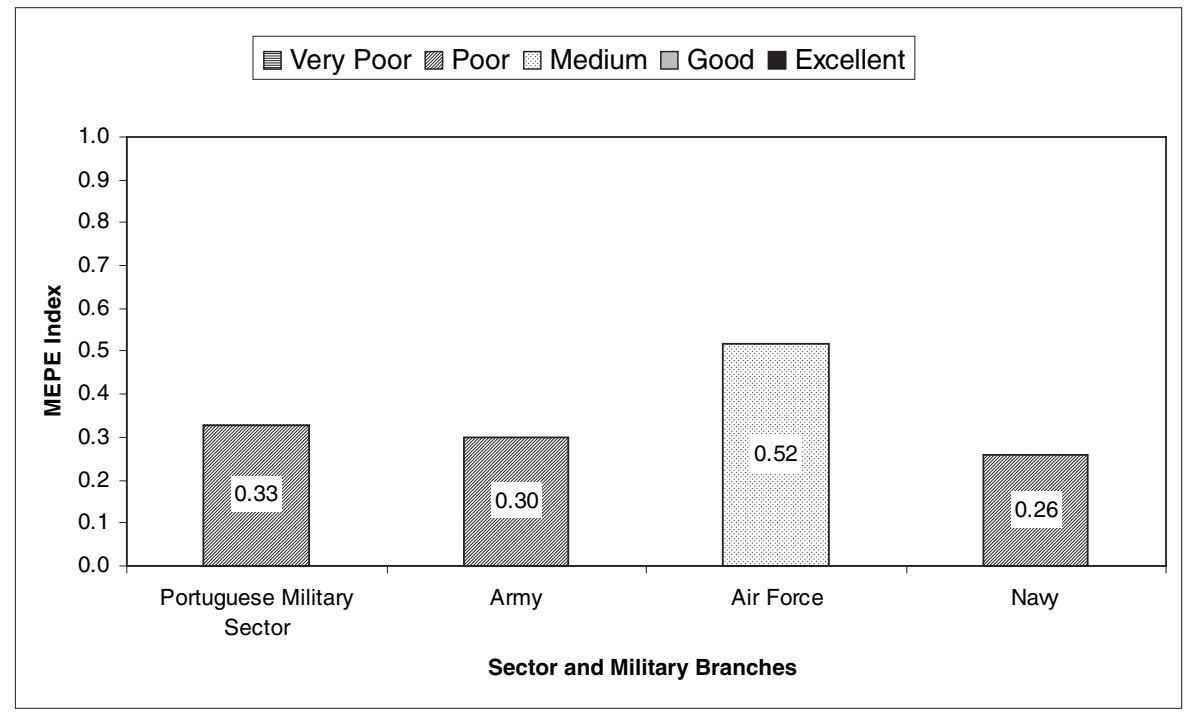

Figure 1. MEPE index for the Portuguese military sector and for the three different military branches.

\begin{tabular}{|c|c|c|c|c|c|}
\hline \multirow{2}{*}{$\begin{array}{l}\text { Dependent variable } \\
\text { MEPE index }\end{array}$} & \multicolumn{2}{|c|}{ Groups } & \multirow{2}{*}{$\begin{array}{c}\text { Sum of ranks } \\
3095.5\end{array}$} & \multirow{2}{*}{$\frac{H}{17.08}$} & \multirow{2}{*}{$\begin{array}{c}\text { Significance } \\
\text { Significant for } p<0.01\end{array}$} \\
\hline & Military branches & Army & & & \\
\hline & & Air Force & 1407.5 & & \\
\hline & & Navy & 3625.0 & & \\
\hline & \multirow[t]{13}{*}{ Personnel } & $\mathrm{CL}_{1}$ & 2190.5 & \multirow[t]{13}{*}{24.31} & \multirow{13}{*}{ Significant for $p<0.05$} \\
\hline & & $\mathrm{CL}_{2}$ & 858.0 & & \\
\hline & & $\mathrm{CL}_{3}$ & 906.5 & & \\
\hline & & $\mathrm{CL}_{4}$ & 385.0 & & \\
\hline & & $\mathrm{CL}_{5}$ & 773.0 & & \\
\hline & & $\mathrm{CL}_{6}$ & 788.0 & & \\
\hline & & $\mathrm{CL}_{7}$ & 219.0 & & \\
\hline & & $\mathrm{CL}_{8}$ & 208.0 & & \\
\hline & & $\mathrm{CL}_{9}$ & 285.5 & & \\
\hline & & $\mathrm{CL}_{10}$ & 439.5 & & \\
\hline & & $\mathrm{CL}_{11}$ & 312.5 & & \\
\hline & & $\mathrm{CL}_{12}$ & 210.5 & & \\
\hline & & $\mathrm{CL}_{21}$ & 50.0 & & \\
\hline & \multirow[t]{4}{*}{ Land area } & $<150$ ha & 3250.500 & \multirow[t]{4}{*}{14.39} & \multirow[t]{4}{*}{ Significant for $p<0.01$} \\
\hline & & $\begin{array}{l}\geq 150 \mathrm{ha} \text { and } \\
\leq 500 \mathrm{ha}\end{array}$ & 685.500 & & \\
\hline & & $\begin{array}{l}>500 \text { ha and } \\
\leq 1000 \text { ha }\end{array}$ & 171.500 & & \\
\hline & & >100o ha & 170.500 & & \\
\hline
\end{tabular}

Table 3. The Kruskal-Wallis test to verify the differences among the MEPE index groups: military branches; personnel (military plus civilian) working in the unit and land area 
ronmental policy, voluntary environmental audits in certain units, implementation of water and waste management systems in its main units and cooperation activities with environmental research institutions.

In fact, according to MEPE results and the detailed disaggregated information presented by Ramos and Melo (in press), the environmental profile of the Portuguese Military presents a poor picture of sectoral environmental integration. The Portuguese Ministry of Defence is beginning to improve the current environmental performance scenario, though in isolation from the rest of the public sector, since there is no greening government strategy for the Portuguese public service overall. Although there are relatively few environmental management practices implemented in the Portuguese military, the sector presents signs of improvement.

There is no similar work available for other countries' armed forces, i.e. studies that compare the environmental performance among the main military branches at a national level. Despite this, some attempts to make comparisons with other military forces have been conducted, keeping in mind various limitations related to the scope of the studies and the different situations in different countries, including size, culture and military development. US DOD (2000) presents the impacts of EMS implementation on the environmental performance of I6 US military installations. This study shows that the degree of implementation of environmental management practices in those 16 installations is quite advanced when compared with the majority of the Portuguese installations. In general, the results obtained for the Portuguese military reveal that they are on the threshold of sectoral environmental integration practices. The following examples show how embryonic environmental considerations in the Portuguese military are: (i) the United Stated Department of Defence (DOD) has significantly developed its environmental programmes in the last I4 years; (ii) the Department of National Defence and the Canadian Forces (DND/CF) began their Sustainable Development Strategy for National Defence in I997 with significant experience in the environmental management of defence operations (see LFC/DND/CF, I999; DND/CF, I997, 2003) and (iii) the UK MOD corporate EMS, based on ISO I400I, is still being implemented across the department and will eventually cover all sites and staff. At present I\% of staff are covered by certified systems (UK Government, 2002).

Apparently, the environmental impacts related to the different activities of each military branch do not justify the different performance among branches. However, according to the findings of Ramos et al. (2004), the Portuguese Army has reported a profile with more environmentally significant impacts and, proportionally, presents more defence activities with high environmental problems. Certain factors could justify this different behaviour, such as (i) a poorer environmental performance than the other branches, (ii) specific military activities that produce more environmental effects or pressures, in particular in units with heavy conventional weapons and ground training activities, and (iii) the organizational structure of this branch, with not very clear environmental responsibilities and a larger number of units spread throughout the territory, which could lead to difficulties in managing environmental issues.

It should be pointed out that it is difficult for any defence organization, especially historically autonomous ones such as the branches of the military, to allow themselves to be subjected to this kind of review. It may be viewed as a chance to show up errors in the command of an individual, and thus become too personal.

\section{MEPE Index by Unit Size}

The total population of the military units surveyed ranges from 8 to 2048 , a size variation of three orders of magnitude. The MEPE results among classes of personnel working in the unit showed two main groups: group I - classes with lower population values, classes $\mathrm{CL}_{\mathrm{I}}-\mathrm{CL}_{6}$, which have lower MEPE values; 


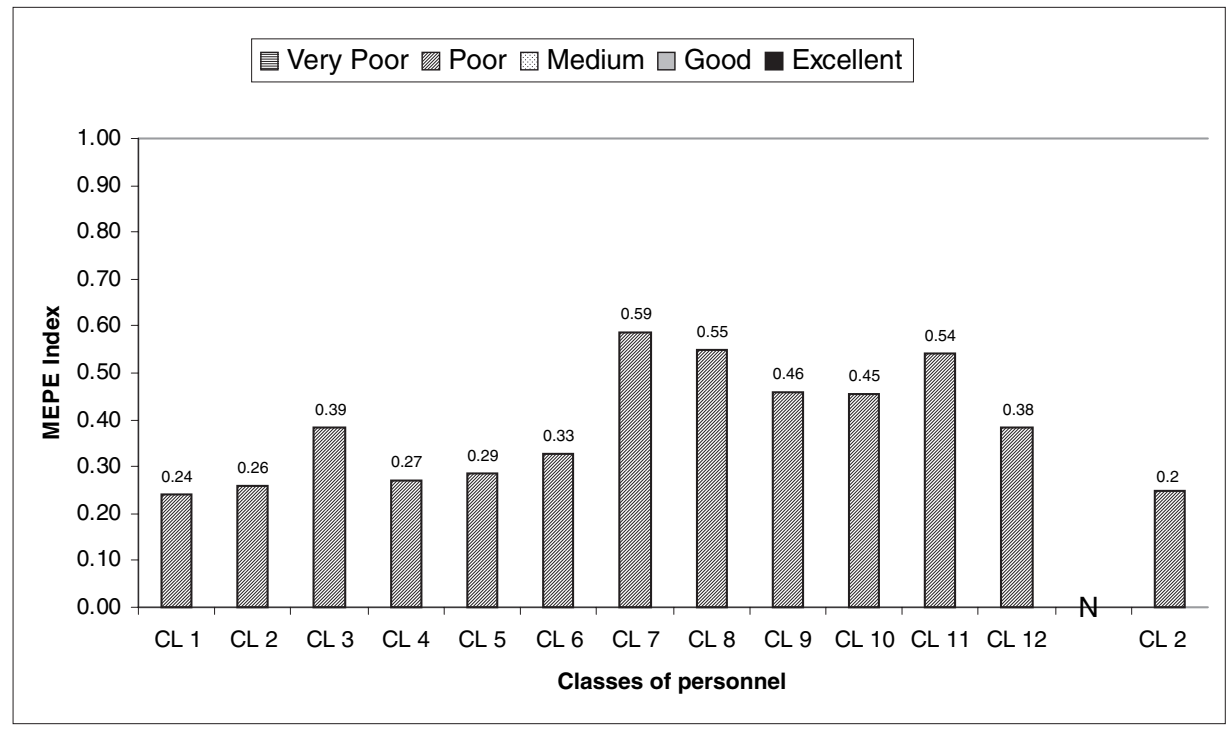

Figure 2. MEPE index by personnel classes.

group II - classes $\mathrm{CL}_{7}-\mathrm{CL}_{\mathrm{II}}$, with higher population values, which have higher MEPE values. Classes $\mathrm{CL}_{\mathrm{I} 2}$ and $\mathrm{CL}_{2 \mathrm{I}}$ are exceptions to this general behaviour, as can be seen in Figure 2, where this last class is represented by a single large Navy unit with few environmental practices implemented. The differences among classes are confirmed by the Kruskal-Wallis test (significant for $p<0.05$ ) (Table 3). In addition, the Spearman $r_{\mathrm{S}}$ correlation test confirmed the significant relationship between the MEPE index and unit personnel (for $p<0.05$ ). The relative contribution of each MEPE category to each personnel class showed that units in the first group are mainly classified as very poor or poor according to the MEPE categories, whereas in the second group the majority are classified as medium or good. The remaining classes $\mathrm{CL}_{\mathrm{I} 2}$ and $\mathrm{CL}_{2 \mathrm{I}}$ are mostly classified as poor.

The total land area of the military units ranges from 0.034 to $7500 \mathrm{ha}$, with an average area of $2 \mathrm{I} 4 \mathrm{ha}$ per unit. This is not applicable for most Navy units since many are ship-based. $84 \%$ of the units have less than I50ha (with an average of II ha), I2\% of the units have an area between I50ha and 500 ha (average 3I7ha), $2 \%$ have between 500 ha and I000 ha (average 7Ioha) and another $2 \%$ of units have more than I000ha (average 6950ha). Higher MEPE values are found in the units with large areas (Figure 3). The differences among these classes are confirmed by the Kruskal-Wallis test (significant for $p<$ o.oI) (Table 3). In addition, the Spearman $r_{\mathrm{S}}$ correlation test confirmed the significant relation between the MEPE index and unit land area (for $p<0.05$ ).

Large industrial organizations in the private sector, usually on account of severe environmental problems and/or intense public pressure, tend to lead in implementing environmental practices. Several authors confirm this for environmental performance evaluation and reporting of private organizations (e.g. Kolk et al., 200I; Noci, 2000). Generally small and medium-sized organizations tend to be less environmentally aware. This pattern could explain the apparently better environmental performance of large military units. Large military installations generally have greater diversity in their military activities and operational responsibilities, leading to greater readiness to accept environmental management practices and probably to more developed environmental awareness. In addition, these results could be explained by the fact that some of the units with large land areas are adopting EMS and have staff in charge of environmental issues. 


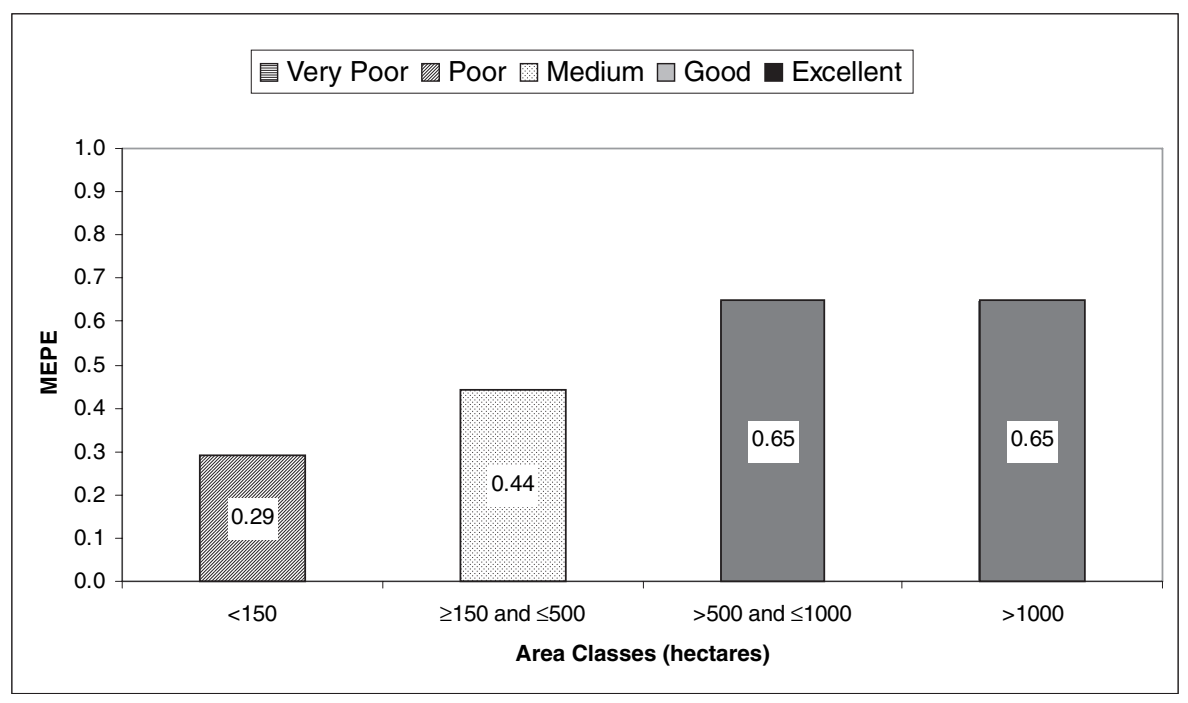

Figure 3. MEPE index by land area classes.

Due to the relatively limited size of Portuguese military installations, extrapolations of the current results to other larger military armed forces should be undertaken with particular care. The larger Portuguese military units would probably be classified as small, for example, by the United States or United Kingdom military forces.

\section{Unit Self-Assessment Versus the MEPE Index}

The comparison between environmental performance self-assessment and the results of the MEPE index shows clear contradictory behaviour (Figure 4). The MEPE results probably reflect a more realistic view, compared with an overoptimistic perspective in the units' self-assessment of environmental performance. According to the MEPE results, most military units are classified as very poor (30\%) or poor (39\%). In contrast, most units consider themselves as showing a medium $(46 \%)$ or good $(38 \%)$ environmental performance. The mean values confirm the relative differences between the two evaluation paths, showing that for the three branches and for the Portuguese military sector MEPE produces lower values than self-assessment (Figure 5).

The comparison of the MEPE index and the self-assessment by branch shows that only the Air Force has a similar pattern. This suggests that environmental data and information reported by the Air Force is more reliable when compared with the other branches. The Spearman $r_{\mathrm{S}}$ correlation test confirmed the non-significant relationship between the MEPE index and the units' self-assessment of environmental performance within each branch (for $p<0.05$ ). This lack of correlation demonstrates the poor credibility of the self-assessment answers.

Evaluation of the MEPE sensitivity showed that there is a significant correlation $(p<0.05)$ between the indicators that compose the index and the MEPE results. The generation of different random values for each indicator computes a non-significant correlation for the majority of the indicators and the MEPE index computed with the real data.

The overoptimistic self-assessment results could be partially explained by the need to convey the high performance, rigour and efficiency associated with the military sector's image. It could also be explained by poor knowledge of their actual environmental performance, which is consistent with the fact that the branch with best performance is the one with the best self-assessment. 


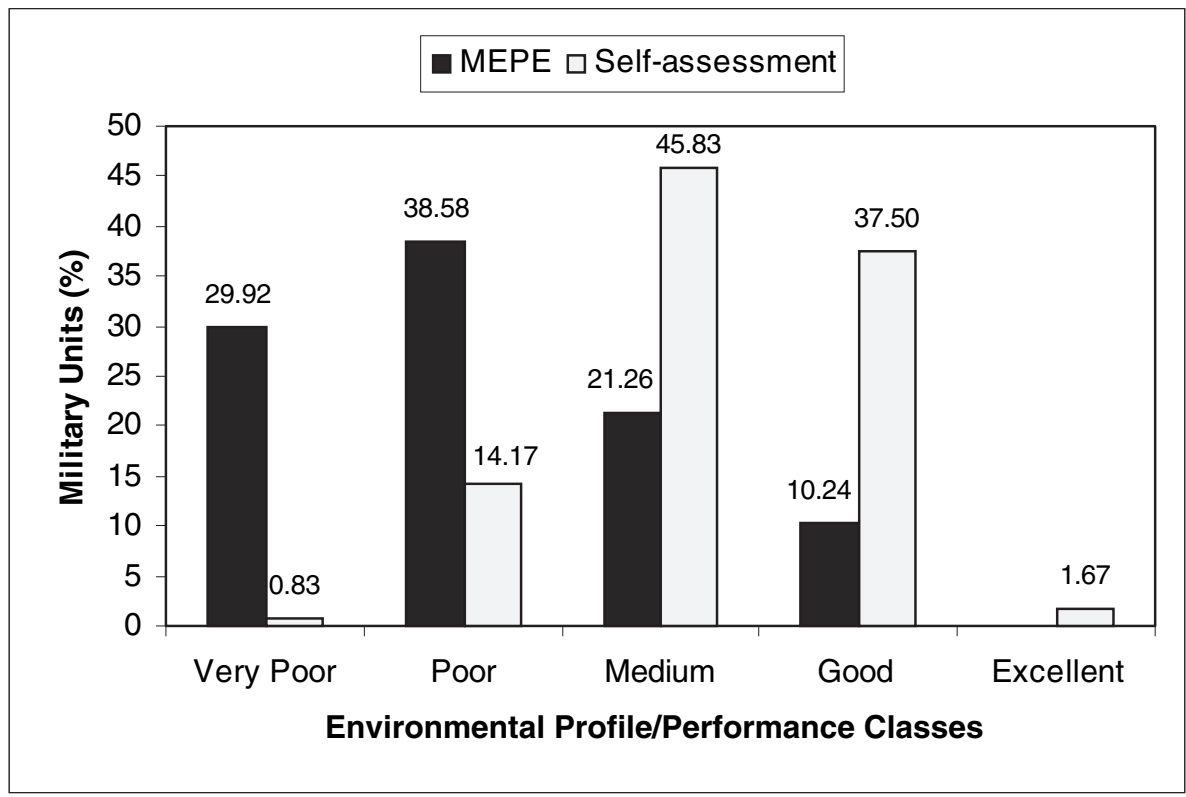

Figure 4. Comparison between the MEPE index and the unit's environmental performance self-assessment.

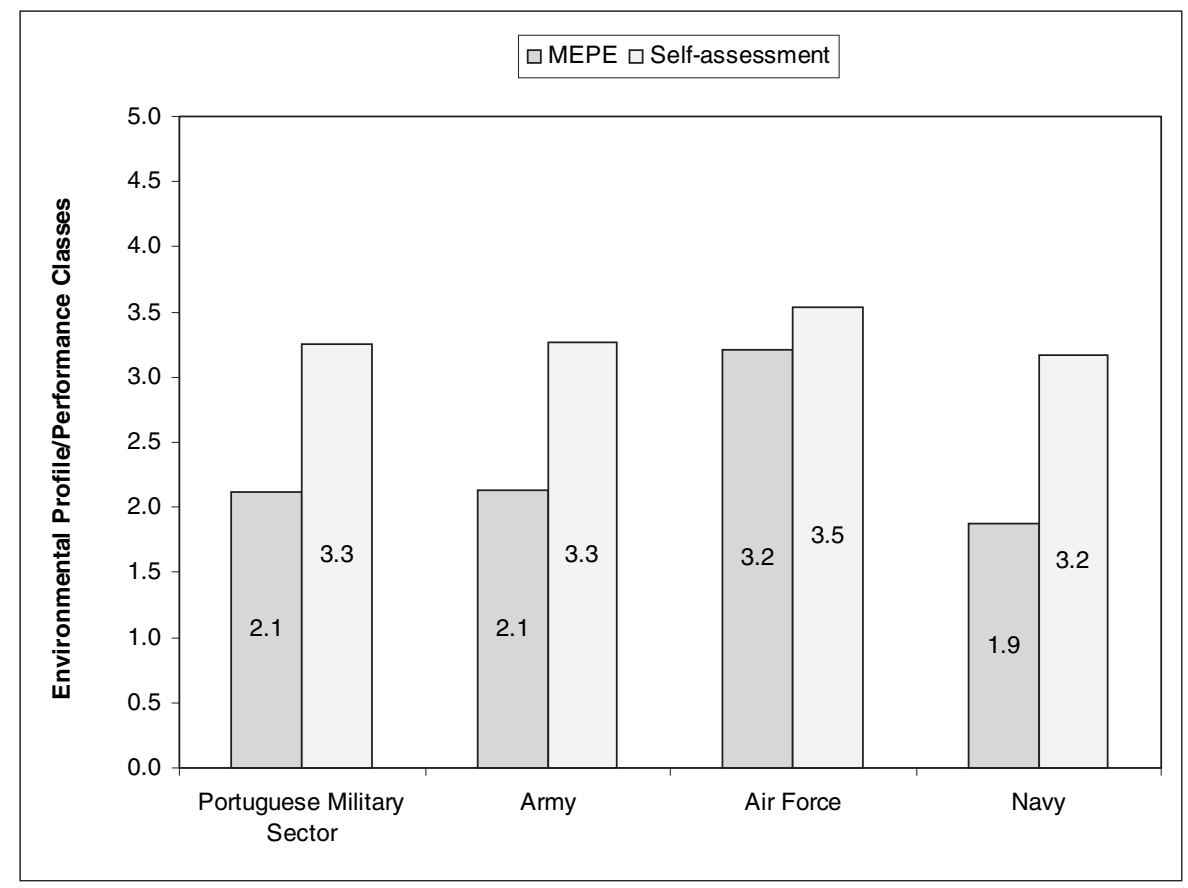

Figure 5. Average values of the MEPE index and of the self-assessment question for the Portuguese military sector and each military branch. Raw data varies from 1 to 5 , for a very poor to excellent environmental performance/environmental profile.

In general, both private and public organizations do not report 'bad news' (Burritt and Welch, 1997). Despite the great experience of business in environmental performance communication, the credibility of performance self-assessment and the related environmental reporting is a quite recent and underexplored issue. Organizations tend to pass the best possible environmental image to interested parties. 
Hughes et al. (2000) stated that the disclosure of environmental performance by organizations does not reveal the complete scenario, and stakeholders frequently criticize the information reported, as mentioned by Ilinitch et al. (1998). The Portuguese military tend to reflect this scenario when they are asked to classify their environmental performance, in many cases without any data available and purely on the basis of their subjective perception. This behaviour is amplified by the military profile, which assumes that the military should set the example for the rest of the nation.

The results obtained bring to the current discussion the general public's perception of the unreliability of information conveyed by the military. NATO (I996) stated that in many countries the public distrusts the military sector. The public is often suspicious that the military is using the screen of security to mask dubious environmental practices. The military should attempt to overcome such suspicion by conveying their environmental performance to stakeholders, assuring credibility and transparency, and not putting a positive bias on the information reported.

At the international level some military forces use checking tools to conduct a unit's self-assessment of its environmental performance. These assessments are considered very important in evaluating the state of their unit's environmental performance (see US Army, 200I; US Air Force, I998), e.g. for assessment of the effectiveness of the unit's environmental programme or the unit's compliance with environmental laws and regulations, among others. These kinds of procedure should be stimulated in order to expand the application of these assessments and associate them with environmental reporting practice.

Nevertheless, the Portuguese military sector primarily needs environmental training, education and awareness, since it is the first step towards improving the current results. Additionally, detailed environmental baseline work must be carried out for each military unit, in particular, environmental assessment of the impact of major missions and activities; surveys to identify and characterize contaminated sites, and natural resource inventories of the main training areas.

It should be stated that all the data provided by this evaluation refers to environmental management practices in Portuguese military units operating during peacetime. Therefore, aspects regarding environmental performance in wartime or combat scenarios could not be directly analysed with this data. Nevertheless, some of the environmental practices identified by the survey produce results in armed military operations that could contribute to a better environmental profile.

\section{Conclusions}

This work assesses the Portuguese military sector's environmental performance through the MEPE index. The index measures the extent to which a variety of environmental practices have been adopted in this sector. This approach tries to help the defence decision-makers to understand the military environmental profile.

The MEPE index reflects the relationship between environmental management practices and military organizations, taking into account a unit's military branch and size (population and land area). The defence sector registers a poor environmental performance, despite several significant environmental initiatives. However, the diverse nature of the units makes evaluation rather difficult and must be taken into account.

The situation in the Portuguese defence sector is, in general, better than the Portuguese public sector. Although there is no quantitative data available to assess the Portuguese public sector's environmental performance, some general indications indicate this pattern. Despite the different scope of the USEPA (I994) study, it is interesting to compare some of the findings and conclusions associated with the current research. The main intention of that work was to determine whether certain organizational 
enabling systems have been established to allow the respondents' groups to fully implement a sound environmental management programme. Results showed that defence related agencies and corporate organizations exhibit significantly more attributes and behaviours than do the civilian federal agencies.

Among the three military branches, the Air Force reveals the best environmental results. The results also showed an apparently better environmental performance for large-scale military units.

The comparison between the units' self-assessment of environmental performance and the MEPE index showed a poor correlation, with consistently overoptimistic self-assessment.

The application of this kind of tool could be used by defence and military authorities in the future to collect and aggregate environmental data for military activities, contributing to the reporting and the assessment of the state of the defence sector from an environmental perspective. These results could complement future developments in specific environmental performance indicators and indices, applied to the whole sector or to a single military unit, which take into account actual environmental pressures and impacts. More broadly, this method might be also applied to an evaluation of the public sector's environmental performance.

\section{Acknowledgments}

We would like to express our thanks for the financial support of the Fundação das Universidades Portuguesas and to the Portuguese Ministry of National Defence (MDN). The first author had a PRAXIS XXI/BD/I5973/98 scholarship, financed by the ESF (European Social Fund). We would like also to acknowledge the valuable collaboration of the following people from the MDN and the military branches: Isabel Leitão, Álvaro Estrela Soares, Cardeira Martins, Carlos Paizinho, José Gouveia, Ramiro Matos, Germano Marta and Reis Fernandes. The authors express their gratitude for constructive comments provided by anonymous reviewers.

\section{References}

Azzone G, Manzini R, Noci G, Welford R, Young CW. I996. Defining environmental performance indicators: an integrated framework. Business Strategy and the Environment 5: 69-80.

Berkhout F, Hertin J, Azzone G, Carlens J, Drunen M, Jasch C, Noci G, Olsthoorn X, Tyteca D, Woerd FVD, Wagner M, Wehrmeyer W, Wolf O. 200I. Measuring the Environmental Performance of Industry (MEPI), final report. EC Environmental and Climate Research Programme: Research Theme 4, Human Dimensions of Environmental Change, Contract No. ENV4-CT97-0655. Science and Technology Policy Research (SPRU), University of Sussex; Department of Economics and Production, Politecnico di Milano; Institut für Oekologische Wirtschaftsforschung (IOeW); Institute for Environmental Studies, Vrije Universiteit Amsterdam; Centre Entreprise-Environnement (CEE), Université Catholique de Louvain; Centre for Environmental Strategy (CES), University of Surrey; IPTS Institute for Prospective Technological Studies.

Burritt RL, Welch S. I997. Accountability for environmental performance of the Australian Commonwealth public sector. Accounting, Auditing and Accountability Journal Io: 532-56r.

Davis-Walling P, Batterman S. I997. Environmental reporting by the Fortune 50 firms. Environmental Management 21: 865-875.

Department of National Defence and the Canadian Forces (DND/CF). I997. Environmentally Sustainable Defence Activities: a Sustainable Development Strategy for National Defence. DND/CF: Canada.

Department of National Defence and the Canadian Forces (DND/CF). 2003. Environmentally Sustainable Defence Activities: Sustainable Development Strategy 2003. DND/CF: Canada.

Ditz D, Ranganathan J. 1997. Measuring Up: Toward a Common Framework for Tracking Corporate Environmental Performance. World Resources Institute: Washington, DC.

Drawbaugh R. I999. Use of environmental management systems and ISO I400I in the public sector: US Department of Defense. In Environmental Management Systems and ISO 1400, Federal Facilities Council Report I38. National Academy Press: Washington, DC; $18-20$.

Epstein MJ. 1996. Measuring Corporate Environmental Performance. Institute of Management Accountants-McGraw-Hill: San Francisco.

Florida R, Davison D. 200I. Why firms adopt advanced environmental practices (and do they make a difference). In Going Private: Environmental Management Systems and the New Policy Agenda, Coglianese C, Nash J (eds). Resources for the Future: Washington, DC: 82-I04. 
Gibbons JD. 1993. Nonparametric Statistics - an Introduction, University Paper Series on Quantitative Applications in the Social Sciences, Series No. 07-090. Sage: Newbury Park, CA.

Hughes SB, Anderson A, Golden S. 2000. Corporate environmental disclosures: are they useful in determining environmental performance. Journal of Accounting and Public Policy 20: 2I7-240.

Ilinitch AY, Soderstrom NS, Thomas TE. I998. Measuring corporate environmental performance. Journal of Accounting and Public Policy 17: 383-408.

Jones DD, Messenger M, Webster R, Stine R. 2002. Installation Sustainability: transforming the army's future. Federal Facilities Environmental Journal Spring: 27-38.

Jones K. I999. Study on Environmental Reporting by Companies. Centre for Environmental Informatics, University of Sunderland-European Commission. Sunderland, UK.

Kolk A, Walhain S, van de Wateringen S. 200I. Environmental reporting by the Fortune Global 250: exploring the influence of nationality and sector. Business Strategy and the Environment Io: 15-28.

KPMG. 1999. KMPG International Survey of Environmental Reporting 1999. Research carried out by the Institute for Environmental Management (WIMM), University of Amsterdam, in collaboration with KPMG International Environment Network. KPMG Environmental Consulting. The Hogue.

KPMG. 2002. KPMG International Survey of Corporate Sustainability Reporting 2002. KPMG Global Sustainability Services and Amsterdam Graduate Business School, University of Amsterdam.

Land Force Command, Department of National Defence and the Canadian Forces (LFC/DND/CF). I999. Environmental Management System - Land Force Command. LFC/DND/CF.

Lederer SE. I997. Use of an environmental management system at an operating military facility. In Annual Joint Service Pollution Prevention Conference. Air Force Center for Environmental Excellence: San Antonio, TX.

Lober DJ, Bynum D, Campbell E, Jacques M. I997. The Ioo Plus corporate environmental report study: a survey of an evolving environmental management tool. Business Strategy and the Environment 6: 57-73.

Ministério da Defesa Nacional (MDN). 200I. A Proteç̧ão Ambiental nas Forças Armadas. MDN: Lisboa.

Ministério da Defesa Nacional (MDN). 2002. Anuário Estatístico da Defesa Nacional de 2001. MDN: Lisboa.

National Academy of Sciences. I999. Industrial Environmental Performance Metrics - Challenges and Opportunities. Committee on Industrial Environmental Performance Metrics, National Academy of Engineering, National Research Council. National Academy Press: Washington, DC.

Niskanen J, Nieminen T. 200I. The objectivity of corporate environmental reporting: a study of Finnish listed firms' environmental disclosures. Business Strategy and the Environment Io: 29-37.

Noci G. 2000. Environmental reporting in Italy: current practice and future developments. Business Strategy and the Environment 9: 2II-223.

North Atlantic Treaty Organization (NATO). 1996. Environmental Guidelines for the Military Sector. NATO Committee on the Challenges of Modern Society. A Joint Sweden-United States Project.

North Atlantic Treaty Organization (NATO). 2000. Environmental Management Systems in the Military Sector, final report of the pilot study group, Report No. 240. NATO Committee on the Challenges of Modern Society.

North Atlantic Treaty Organization (NATO). 2002. STANAG 7141 EP (Edition 1) (Ratification Draft 1) - Joint NATO Doctrine for Environmental Protection During NATO Led Operations and Exercises. NATO Standardization Agency, Joint Service Board: Brussels.

Olsthoorn X, Tyteca D, Wehrmeyer W, Wagner M. 200I. Environmental indicators for business: a review of the literature and standardisation methods. Journal of Cleaner Production 9: 453-463.

Performance Measurement for Sustainable Government Operations (PMSGO). I999. Environmental Performance Measures for Government Operations - a Guidance Document, Version I.o. Prepared by Marbek Resource Consultants for the Committee on PMSGO, Canada.

Perry M, Sheng TT. 1999. An overview of trends related to environmental reporting in Singapore. Environmental Management and Health 5. 10: 310-320.

Ramos TB, Alves I, Subtil R, Melo JJ. 2004. Environmental aspects and impacts of public sector organizations: the Portuguese defence sector profile. In The 2004 International Sustainable Development Research Conference, Manchester. ERP Environment; 484-495. Manchester, UK.

Ramos TB, Melo JJ. In press. Environmental management practice in the defence sector: assessment of the Portuguese military's environmental profile. Journal of Cleaner Production.

Ranganathan J. 1998. Sustainability Rulers: Measuring Corporate Environmental and Social Performance. Sustainable Enterprise Perspectives. World Resources Institute: Washington, DC.

Rea LM, Parker RA. I997. Designing and Conducting Survey Research. Jossey-Bass: San Francisco, CA.

Richards LE, Armstrong W. I996. Environmental management in the minerals industry: theory and practice. Business Strategy and the Environment 5: 87-93. 
Rowe J, Enticott R. I998. Evaluating the links between locality and environmental performance of SMEs: some observations from survey and partnership programmes in the Greater Bristol area. Eco-Management and Auditing 5: II2-I25.

Stanwick SD, Stanwick PA. 2000. The relationship between environmental disclosures and financial performance: an empirical study of US firms. Eco-Management and Auditing 7: 155-164.

Steucke PT. 2000. Public sector value of an ISO I4000 certified environmental management system: the Fort Lewis army installation in Washington State. Environmental Practice 2: 288-290.

Taylor C, Kivela K, Kontess W, Crum J. 200I. Environmental Management Systems and the Air Force Environmental Program. 200I. https://www.denix.osd.mil/denix/Public/Library/PRO97/ems.html [Io October 200I.]

Theyel G. 2000. Management practices for environmental innovation and performance. International Journal of Operations and Production Management 20: 249-266.

Tyteca D. I996. On the measurement of the environmental performance of firms - a literature review and a productive efficiency perspective. Journal of Environmental Management 46: 28I-308.

UK Government. 2002. Sustainable Development in Government - First Annual Report 2002. Ministerial Sub-Committee of Green Ministers, $\operatorname{ENV}(\mathrm{G})$.

United Nations Environment Program (UNEP), SustainAbility. 1997. Engaging Stakeholders: the 1997 Benchmark Survey - the Third International Progress Report on Company Environmental Reporting. SustainAbility-UNEP. London.

United States Air Force (US Air Force). 1998. Environmental Management Self Assessment Tool (EMSAT), user manual, Version I.8. Developed in a joint effort between the Air Force Center for Environmental Excellence, Air Combat Command and $\mathrm{CH} 2 \mathrm{M}$ HILL.

United States Army (US Army). 200I. Environmental Considerations in Military Operations. Headquarters, Department of the Army: Washington, DC.

United States Department of Defense (US DOD). 2000. ISO 14001 Environmental Management Systems Pilot Study, final report. US Department of Defense: Washington, DC.

United States Department of Defense (US DOD), Swedish Armed Forces (SAF). I999. Environmental Considerations in the Systems Acquisition Process - a Handbook for Program Managers. SAF-US DOD: Washington, DC.

United States Environmental Protection Agency (USEPA). I994. Environmental Management System Benchmark Report: a Review of Federal Agencies and Selected Private Corporations, EPA-300R-94-009. USEPA, Office of Enforcement and Compliance Assurance: Washington, DC.

United States Marine Corps (US MC). 2000. Short Guide to Environmental Management Systems (EMS). Headquarters US MC, Installations and Logistics Department. Washington, DC.

Wheater CP, Cook P. 2000. Using Statistics to Understand the Environment. Routledge: London.

Wilson GW, Sasseville DR. I999. Sustaining Environmental Management Success: Best Business Practices from Industry Leaders. Wiley: New York.

Young CW, Welford RJ. 1998. An environmental performance measurement framework for business. Greener Management International 2I: 30-49. 